\title{
The Role of Medical Literature, Clinical Trials and Experimental Research in Drug Product-Injury Litigation: A Primer with Two Examples
}

\author{
Jan M. Kitzen1,2, Joseph V. Pergolizzi Jr. ${ }^{3}$, Robert Taylor Jr. ${ }^{3}$, Robert B. Raffa ${ }^{4,5}$ \\ ${ }^{1}$ Kitzen Pharmaceutical Consulting, Collegeville, USA \\ ${ }^{2}$ Temple University School of Medicine, Philadelphia, USA \\ ${ }^{3}$ NEMA Research, Inc., Naples, USA \\ ${ }^{4}$ University of Arizona College of Pharmacy, Tucson, USA \\ ${ }^{5}$ Temple University School of Pharmacy, Philadelphia,USA \\ Email: jkitzen@verizon.net
}

How to cite this paper: Kitzen, J.M., Pergolizzi Jr., J.V., Taylor Jr., R. and Raffa, R.B. (2018) The Role of Medical Literature, Clinical Trials and Experimental Research in Drug Product-Injury Litigation: A Primer with Two Examples. Pharmacology \& Pharmacy, 9, 208-227.

https://doi.org/10.4236/pp.2018.96016

Received: May 28, 2018

Accepted: June 26, 2018

Published: June 29, 2018

Copyright $(9) 2018$ by authors and Scientific Research Publishing Inc. This work is licensed under the Creative Commons Attribution International License (CC BY 4.0).

http://creativecommons.org/licenses/by/4.0/

\begin{abstract}
When any type of product has been ordered to be removed from the marketplace by a governmental regulatory body, that action is a powerful indicator that the product has been determined to be unsafe for further use, thereby branding the product as defective and opening up the possibility of product liability litigation. When the product is a drug or medical device, it is especially serious since the possibility of personal injury (acute and/or chronic) or death may occur. Needless to say, in these situations, product injury litigation will almost surely follow. We review the definition and requisite claims needed to establish drug product liability, and the role that the medical literature, clinical trial data, and even experimental research data can play in product (drug)-injury litigation. We show how each of these resources played a significant role in two well-known cases: Fen-Phen and thimerosal. The ultimate goal of such knowledge is to make better informed decisions about drug safety.
\end{abstract}

\section{Keywords}

Drug Safety, Product Quality, Injury, Litigation, Fen-Phen, Thimerosal

\section{Introduction}

Definition of product liability: The legal responsibility of manufacturers and sel- 
lers to buyers, users, and bystanders for damages or injuries suffered because of defects in goods.

There are many FDA approved drugs currently involved in litigation despite the fact that many of these cases are related to warnings and adverse events contained in the product labeling [1]. In order to prevail on a product liability claim, the product complained about must unreasonably threaten the personal safety of a consumer and must be shown to be defective. Manufacturers and suppliers can incur liability through three types of product defects:

1) Design defects-resulting from inherent properties of the drug's molecular structure, or improper preclinical or clinical development. This is probably the most common type of defect encountered in new drugs introduced to the market.

2) Manufacturing defects-these may occur during the manufacturing process and may result from improper cleaning or maintenance of manufacturing equipment used in the large-scale production of large quantities of drugs. Lack of adherence to current Good Manufacturing Practices (cGMP) may result in manufacturing defects. These are usually more limited in scope than design defects, and the defect may be confined to one or more batches of the manufactured product.

3) Marketing defects-resulting from improper marketing and claims made for specific drug products. This category often involves injuries caused by a failure to provide adequate or accurate warnings regarding a dangerous side effect, or to a failure to provide adequate instructions regarding the safe and appropriate use of the drug. Many products, even the most ordinary ones, pose some levels of risk, and the law recognizes that it is often not possible to design a totally safe product. However, manufacturers are legally obligated to warn consumers about known dangers. If they do not warn consumers, manufacturers may be found negligent in the following circumstances:

- they fail to warn users about recognized risk

- the warning is too vague to be adequate

- the warning is not brought to the user's attention

Defective product lawsuits may include a combination of claims. For example, a claim based on a drug with a dangerous side effect may be coupled with a claim based on the failure to warn of that side effect. There are four elements of a negligent tort as applied to product liability cases:

1) a duty owed by the particular defendant to the particular plaintiff to act as a reasonably prudent person under the same or similar circumstance

2) a breach of such a duty (by the defendant) that constitutes a failure to act reasonably

3) injury, including personal injury or property damage

4) a causal link between the defendant's breach of duty and injuries sustained by the plaintiff

Because design and marketing defects are the most serious of liability defects and usually include the largest number of people exposed to the product, the 
remainder of this article will only be concerned with defects in these categories and will focus specifically on drug-related personal injury.

\subsection{The FDA and Decisions Regarding Severity of Liability}

Based on post-marketing surveillance reports sent to the Food and Drug Administration (FDA), usually in the form of MedWatch reports for drugs or reports using the vaccine adverse event reporting system (VAERS) for vaccines, the agency may impose one of three possible decisions on a manufacturer. The most serious decision is the issuance of an order to the manufacturer to immediately recall the product from the market. A less forceful, but equally serious option is for the agency to request that the manufacturer voluntarily remove the product from the market. In either case, the manufacturer issues recall notices to all providers of the product (wholesalers, distributers, pharmacies, physician samples, etc.) for them to immediately quarantine the product and prevent any further distribution to customers as soon as possible. When the FDA makes its decision, chances are highly likely that the public-at-large will become aware of this via various news alerts and press releases. The final type of decision that the agency may make regarding a product's safety is to issue a restricted-use order that limits the use of a particular product to only a small portion of patients in whom other treatments have been deemed ineffective. The manufacturer may also be required to expand its post-marketing surveillance activities and monitor closely the now limited population of patients exposed to the drug.

\subsection{Adverse Drug Reaction Reports and the Internet}

Widespread access to Internet resources has greatly facilitated the ability of individuals and public-interest groups to obtain the most recent available information regarding drug safety and the incidence of adverse reaction reporting. The following government web page is a useful site for both reporting drug adverse events and for accessing drug safety information:

https://www.fda.gov/Safety/MedWatch/default.htm. The FDA monitors all adverse events through its MedWatch reporting system. This database accepts reports from patients, pharmacists, and physicians, as well as other professionals and health care practitioners. As an example of the volume of reports, in 2014 the FDA received nearly 1.3 million adverse event reports (AERs) [2]. Of these, 1,204,685 were entered in the MedWatch database. The large number and accessibility of MedWatch reports increases the likelihood that drug-related adverse events will lead to liability litigation cases. The incidence and magnitude of the litigation cannot be determined solely from the number of AERs reported of course, as many other factors must be considered, such as the nature of the adverse event(s), whether or not they are reported multiple times for a single product, and the severity and reversibility of an adverse event, among others. Many of the adverse events reported may already have been predicted from the clinical trials of the drug. 
Once a drug is approved for marketing, the total number of people exposed to the product increases markedly. This is why the FDA requires each drug manufacturer to continue to monitor the safety of every drug it has approved throughout its market life. This is known as post-marketing surveillance. This information must be reported to the manufacturers, and they are responsible for monitoring the data and continuing to evaluate the benefit-to-risk relationship. The FDA requires manufacturers to update each product's labeling on an ongoing basis as new safety information is received. An additional useful source of information regarding drug safety is The Institute for Safe Medication Practices (ISMP), a nonprofit organization that is a valuable resource at https://www.ismp.org/. There are numerous reports, safety updates and other resources available at no charge to the user.

\section{Evidence-Based Medicine and Drug Liability Litigation}

\subsection{Demand for Scientific Standards}

Insurance companies are increasingly demanding that scientific standards be established for product liability litigation. They argue that litigation can be unfairly biased against defendants if subjective or unreliable information can be introduced, leaving the technical merit to be judged by the jury without a rigorous scientific analysis using agreed-upon standards and procedures. In the 1990's there were two important landmark Supreme Court rulings in the United States that came to set the standards governing the submission of evidence in lower court testimony. In the first case, Daubert v Merrell Dow (1993) [3] the plaintiff claimed that the combination drug Bendectin ${ }^{\circledR}$ (pyridoxine + doxylamine) used for nausea and vomiting of pregnancy caused birth defects. Defendant's evidence presented in this case consisted primarily of epidemiological studies involving more than 30 published studies and 130,000 patients that indicated no evidence of causation. The plaintiff evidence largely consisted of expert testimony based upon in vitro and in vivo studies suggesting a link between Bendectin ${ }^{\circledR}$ and birth defects, plus a reanalysis of the previously published epidemiologic studies. The Court ruled that the plaintiff's evidence was inadmissible to the court because it had never been published or subjected to peer review. In the second case of Kumho v. Carmichael (1999) [4] the plaintiff claimed that a defective tire blew out leading to a severe auto accident, injury and death. In this case the court ruling distinguished between "scientific" evidence, which must meet standards set by the Supreme Court in Daubert v Merrell Dow, and "engineering" evidence, which need not. "Engineering" referred to technical evaluations offered by expert witnesses, without a systematic examination of the specific materials involved in the case. In the oral argument at the Supreme Court for Kumho v. Carmichael, this distinction was rigorously questioned. In the final ruling, the Supreme Court reversed the Circuit Court's verdict in the case (in favor of the plaintiff), ruling that plaintiff's expert witness analysis failed to meet the standards set forth in the Daubert decision. The arguments furthered the debate over 
scientific standards and seemed to provide insurers with some legal ammunition [5]. In each of these cases the final decisions by the Supreme Court were in favor of the defendants due to the inadmissible evidence provided by the plaintiffs.

It is generally recognized that medicine today is generally practiced by following a set of established guidelines based on evidence-based medicine. This means that all decisions regarding diagnoses, treatment (including surgery and pharmacotherapy) and follow-up procedures are determined by the judicious application of the best-available medical-scientific principles that have been established by various professional and regulatory governing organizations such as The Joint National Committee 8 (JNC8) [6], The American Heart Association, The American Society for Echocardiography, The American Society for Pediatrics, and so forth for each clinical discipline within medical practice. One of the principles involved in evidence-based medicine includes the concept of strength of the evidence. This important method of evaluating the quality of medical evidence is essential to both plaintiffs as well as defendants. To be classified as an evidence-based medical practice, a medication or intervention must be thoroughly evaluated using the scientific method. Medical decisions are based on the multiple reviews of several sources of information and focus on a comprehensive assessment of the quality of the information provided [7]. The safety of each drug is then evaluated based on weighing the relative risks and therapeutic benefits revealed during clinical trials, which should be randomized and placebo-controlled. Experts review data from these studies to determine whether or not the treatment can generally be recognized as safe and effective.

\subsection{Evaluating the Medical Literature}

Unfortunately, the fact that an investigator's experimental (laboratory science) or clinical findings are published in a peer-reviewed journal is not necessarily an indicator that high quality research was carried out during the research process, which may have lasted for months or years. One must also consider other aspects related to publication that can provide better insight into the quality of a journal citation. Such factors (variables) can include a journal's manuscript rejection rate, the number of reviewers the manuscript was submitted to, the average turnaround time from initial receipt of a manuscript to final publication, the journal's "impact factor", the composition of journal's editorial review board, the number of times the journal is cited elsewhere in the literature (science citation index), and other semi-objective factors that contribute to a better understanding of the quality of a journal's citation. This type of scrutiny exceeds that required by the Daubert decision. When these variables are factored in, it becomes possible to show that some peer-reviewed journals are of higher quality than others. Therefore, it can be shown for example that an article published in a journal that encourages submissions that provoke thought and propose novel hypotheses, even if not substantiated with overwhelmingly convincing data, is less likely to have a significant scientific (or by extension, litigation) impact compared to an article published in a journal that requires meticulous attention 
to experimental methods and rigorous use of statistics.

\section{Case Study I: The Diet Drug (Fen-Phen) Litigation}

The drug combination fenfluramine/phentermine ("fen-phen") was an anti-obesity treatment alleged to cause potentially fatal pulmonary hypertension and heart valve problems.

\subsection{Potential Sources of Scientific Evidence}

In cases involving drug product-injury, drug manufacturers (defendants) sometimes feel limited in terms of what they can do to produce new evidence in an effort to show that their drug is not culpable as the primary source of alleged injury. Manufacturers might feel that they cannot conduct new research or clinical trials in an attempt to show that their product is not the cause of the alleged injury. Not only could this be a fruitless attempt to prove a negative, but it might put them at risk of having to deal with an unexplainable or artefactual result, possibly resulting in further damage to the case. An exception to this may be plausible if at the time of drug market withdrawal clinical trials with the product are still in progress. In this situation, the manufacturer may decide to continue to follow these patients in the absence of drug, in order to gather additional safety data in order to determine if it really is exposure to the drug that resulted in an increased incidence or severity of the alleged drug injury, or whether it is inherent in the medical conditions of the patient population. This is exemplified in the decision by Wyeth Pharmaceuticals in 1997 to continue to follow patients participating in a clinical trial involving the diet drug fenfluramine (Redux ${ }^{\circledR}$, a sustained-release formulation of dexfenfluramine, withdrawn from the market in September 1997), which was reported to be associated with an increased risk of myocardial valvular regurgitation [8] [9].

\subsection{Defendants Use of the Medical Literature}

A comprehensive retrospective review of all pre-clinical studies and clinical trials with fenfluramine uncovered no evidence that would suggest that the drug would cause the claimed heart valve abnormalities, and no further studies were conducted. Therefore, the defendant needed to rely on the available data in the medical literature. No further trials, other than follow-up studies, were conducted in an attempt to collect data showing that fenfluramine was not associated with an increase in the incidence of the alleged cardiac valvular regurgitation. In one follow-up study [9], the results showed that, in 1142 patients who were followed for up to 26 months after discontinuing the study drug (fenfluramine, fenfluramine + phentermine, or placebo), no further progression of valvular abnormalities was observed compared to the valvular abnormalities observed approximately one month after the drug was discontinued.

It should be mentioned that plaintiffs are under no obligation to conduct any of their own research to identify further evidence to support their case for a de- 
fective drug product. The burden of proof rests solely with the manufacturer of the product. Accordingly, all new findings from defendant-sponsored studies were required to be submitted to the courts and plaintiff counsel as part of the Discovery Process. In the event that plaintiffs decide to conduct their own research (see Case Study II), they should be aware that all research they perform should adhere to the Daubert criteria in order to be admissible in court. Nevertheless, numerous independent investigators with no vested interest in the litigation found this to be a very interesting research subject, and many original research articles were published on the effects of fenfluramine on cardiac valvular tissue. These publications had no effect on the outcome of the litigation even though their findings were published in peer reviewed journals [10] [11].

\section{Conducting Literature Searches and Managing the Literature for Case Analyses}

There is an enormous amount of medical information available from various databases that are searchable using a variety of methods. Some of the most commonly and widely used medical literature databases are EMBASE, MedLine and PubMed (made available through the National Institutes for Health), among others. There are also epidemiological databases such as those offered by Timely Data Resources, Inc. This company organizes epidemiological inpatient and outpatient data that is searchable by disease, keywords or ICD (International Classification of Diseases) coding. Other databases that are made freely available to the public by the American Heart Association, the Centers for Disease Control (CDC) and many others, offer endless possibilities to gather information on most medical conditions, and the incidence and prevalence data for essentially any disease or condition. In some cases, it is even useful to search the United States Office of Patents and Trademarks as most of the patents are available electronically and can be searched in the usual manner. These can provide insight into whether or not a researcher may have a financial interest (potential bias).

Typically, different literature databases may use different keywords or Boolean logic to describe similar conditions, so some knowledge of the appropriate search terms and how they may be combined is necessary. Reference books are available that identify keywords and their associated medical conditions. Here is a simple example of the use of different keywords to describe similar conditions. In one database, the term mitral insufficiency is used to identify articles related to mitral regurgitation. In another database, the term mitral regurgitation may be used to identify these same articles while the term mitral insufficiency may not. For this reason, it is sometimes more efficient to first browse through several relevant articles and create a list of keywords, then search more broadly using these pre-specified keywords.

Once the literature is identified and available electronically, all or only the most relevant citations can be downloaded and imported into specialized soft- 
ware for storing literature citations. Two examples of such software applications include EndNote ${ }^{\oplus}$ and Reference Manager ${ }^{\oplus}$. These software applications allow the user to download reference citations from the Internet and store complete literature citations, Abstracts and even the ability to import pdfs (when available) as identified in literature searches. Numerous fields are available for sorting, adding search terms and organizing the articles, and they usually contain formatting styles that allow the user to export citations according to desired formatting requirements.

It is generally a good idea to create separate libraries for different litigation cases in order to avoid mixing up of articles or cluttering the reference library with excessive citations that will slow down the searching process. Articles are automatically assigned reference numbers that can be manually added to the first page of a hardcopy of the article, making filing and retrieving articles a simple process. The use of such software applications with well-organized search terms makes the organization and management of the large medical literature an easier task.

In the Fen-Phen drug litigation discussed above, the defendants adopted a strategy that consisted of long-term monitoring of all patients who were participating in clinical trials at the time that fenfluramine was withdrawn from the market. The defendants extensively searched the medical literature to gather data on a wide variety of medical conditions, adverse events associated with medical and surgical procedures, and a great deal of cardiovascular epidemiological data. As the clinical trial data and literature information were gathered, the information was organized using the strength of evidence pyramid [12] (in this approach, medical articles are classified or partitioned into categories based on the strength of evidence). Per this pyramid, all articles and data were organized in ascending order from those considered to contain the weakest supportive evidence to those considered to contain the strongest level of evidence as follows: case reports $\leq$ case series $\leq$ case controlled studies $<$ cohort studies $<$ randomized controlled trials (including double-blind, placebo controlled trials) $<$ systematic reviews. Through such a rigorous and extensive use of the medical literature, valuable information was obtained that provided insight into the prevalence of valvular abnormalities in the untreated general population (background prevalence), as well as information on pre-existing confounding medical conditions that can be associated with or exacerbate cardiac valvular abnormalities, such as a prior history of rheumatic heart disease or concurrent mitral valve prolapse.

Despite the large body of scientific evidence assembled by the defendants, the court ruled in favor of the plaintiffs, and defendant subsequently agreed to a class action settlement. Even though this was an unfavorable decision for defendant in this litigation, the body of medical and scientific information that was gathered turned out to be useful both in the construction of the language of the settlement and in the detection of fraud uncovered after the settlement was in place. Due to the emergence of numerous unexpected medical conditions and 
geographical patterns associated with many of the settlement cases, it was found necessary to continue to monitor the medical literature throughout the first several years of the administration of the settlement.

\section{Types of Work Product}

In order for the massive amount of literature to be useful for attorneys to present in court to the judge overseeing the litigation, to a court-appointed arbitrator, or to a jury, the information must be condensed and organized in a concise manner so that all critical information is readily accessible and comprehensible. Therefore, the decision about the formatting of the work product should be left to the attorneys, since they are most familiar with, and reliant on, how the information needs to be utilized. Various types of formats should be offered for each specific need. For example, if a summary of blood pressure data is needed, this is usually best organized into a table arranged by either year of publication or in order of strength of evidence. All references in the table must be cited, and the original articles should be readily available in case they are needed by the court. Work products may be in the form of data extractions (table format) summaries, white papers for more lengthy analyses, or figures when chemical structures are helpful, pharmacokinetic plots showing blood concentration over time, or even chemical reactions to illustrate how a potential toxin or drug is metabolized.

Every fact or statement in the work product must be supported properly, and copies of the original articles must be readily available. When information about drug concentrations is used, it is often helpful to prepare tables that show interconversion of measurement units, since these may be expressed differently in different articles. It is not unusual to find one article expressing blood or tissue concentrations in units of micrograms/milliliter $(\mu \mathrm{g} / \mathrm{mL})$, micromoles/liter $(\mu$ moles $/ \mathrm{L})$, parts per million $(\mathrm{ppm})$ or as a dilution $(1: 100)$ or percentage. A Table that includes how all of these units compare to each other is very useful. Occasionally it may be necessary to include conversion equations as part of the work product in order to prepare counsel for unexpected new information. The main point to keep in mind is that the purpose of the work product is to provide attorneys with quick and easy access to the information needed in as comprehensible and useful a form as possible.

\section{Case Study II: Thimerosal-and-Autism Litigation}

In another milestone case involving the same defendants as in the Fen-Phen case, the use of the medical literature led to a more favorable outcome for defendant. One reason this was considered a milestone case was that it involved multiple co-defendants, including all manufacturers of thimerosal-containing vaccines and all manufacturers of thimerosal chemical substance. The case was emotionally charged, and became politically charged, with members of the United States Congress taking a personal interest in the litigation, and attorneys-general from several states taking an active interest, with the possibility that 
plaintiffs were seeking financial damages potentially approaching the trillion-dollar (USD) mark. This landmark case received a great deal of attention by the news media, advocacy groups, professional actors, and talk radio hosts. Much of the information was entered into the public domain throughout the course of litigation, since the plaintiffs published numerous articles and also traveled around the USA presenting their findings at various meetings, as well as to the National Institute of Mental Health (NIMH) and to autism activist groups. This all put an additional stress on the sources and reliability of the scientific evidence.

\subsection{Background}

The case involved the issue of whether the mercury-containing preservative thimerosal was a possible risk factor in contributing to a perceived increase in the incidence of autism spectrum disorders (ASD) in young children who were vaccinated with multiple thimerosal-containing vaccines as infants. At the time this litigation was initiated, the affected children ranged from $4-8$ years of age, and signs of autism were beginning to become evident. Thimerosal was a logical choice as the alleged cause of neuronal injury shortly after birth since the Centers for Disease Control (CDC) had recommended in the early 1990s an increase in the number of vaccinations to be administered within the first 6 months of life. Review of available data showed that maximum exposure to mercury $(\mathrm{Hg})$ in infants less than 7 months old varied from $75 \mu \mathrm{g}$ in 1990 to a peak of $187.5 \mu \mathrm{g}$ by 1999 [13] [14]. It was hypothesized by plaintiffs that this extra exposure to thimerosal in the late 1990s could have resulted in neuronal injury in postnatal development of the brain, leading to autism. According to the thimerosal-related hypothesis, it was postulated that some genetically susceptible population of children reacted to the thimerosal in vaccines with increased accumulation and decreased excretion of mercury from the body, which can then alter several biochemical pathways critical for normal brain development [15] [16]. They also hypothesized at this time that autistic children would show higher levels of mercury in their hair relative to non-autistic children [16]. By 2004, which were several years after thimerosal was removed from vaccines and all thimerosal-containing vaccine stock was exhausted, the exposure had decreased to less than $17.9 \mu \mathrm{g}$ [13].

In order to provide perspective for the discussion that follows here, a few facts about the chemistry of thimerosal is helpful. Thimerosal is an organic compound that contains $50 \%$ ethylmercury by weight, and is an antibacterial compound that has been used effectively for that purpose in multi-dose vaccine preparations for over 50 years. After thimerosal enters the body through vaccination, it is metabolized to ethylmercury and thiosalicylate. Ethylmercury is primarily excreted though biliary excretion and is ultimately eliminated from the body through the feces. It is also further metabolized by the oxidative drug metabolizing systems which then facilitate additional excretion in the urine [17]. A portion of the remaining mercury can be retained within the body, because it 
binds to sulfhydryl (S-H) groups located in proteins in various tissues, especially skeletal muscle. Mercury-containing compounds were previously used in a variety of medicinal agents in the 1950s and 1960s, and were frequently found in antiseptic solutions, such as Merthiolate ${ }^{\oplus}$ and Mercurochrome ${ }^{\oplus}$. They were also used as diuretic agents (e.g., Mercuhydrin ${ }^{\oplus}$ ) for many years.

As awareness of mercury toxicity increased in the 1970s and 1980s, mercury-containing products were gradually phased out from medical use with the exception of thimerosal, which continued to be used as a preservative in vaccines. In 1997, the US Food and Drug Administration Modernization Act mandated identification and quantification of mercury in all food and drugs. Two years later, the US Food and Drug Administration found that children might be receiving as much as $187.5 \mu \mathrm{g}$ of mercury within the first 6 months of life. Despite the absence of data suggesting harm from the quantities of ethylmercury that are derived from vaccines, in 1999 the American Academy of Pediatrics and the Public Health Service recommended the immediate removal of mercury from all vaccines given to young infants [18]. This goal was achieved in 2001.

\subsection{The Plaintiff Hypothesis and Use of Experimental Data and the Medical Literature to Support Their Case}

To appreciate the role of scientific evidence in the litigation of this particular case, it is important to point out that the toxicity of mercury has never been in dispute by anyone. Mercury is clearly a highly potent toxic substance. The controversy concern (ed/s) the relative toxicity of the various organic and inorganic forms of mercury that can release mercury in different states of valence, that is, either in the mercurous form, with a single positive charge $\left(\mathrm{Hg}^{+}\right)$, or in the mercuric form, with two positive charges $\left(\mathrm{Hg}^{++}\right)$. They differ in chemical reactivity and biological activity.

The manner in which the plaintiffs developed their strategy to implicate thimerosal as the likely cause of autism is an extremely interesting example of how the adversary design of the legal system influenced the interpretation (the opponents might claim manipulation) of the epidemiologic data, and the design of research initiated in an attempt to obtain new data more favorable to their side. In order to bolster their argument that thimerosal was involved, the plaintiffs began by citing the epidemiologic studies that suggested a rapid increase in the incidence of autism from the 1990's to the early 2000s, which coincides with the increase in exposure to thimerosal secondary to the increase in the number of vaccinations administered to infants. They cited the following evidence to support their case: for decades after Kanner's original paper on the subject was published in 1943 [19], autism was generally considered to be a rare condition with a prevalence of around $0.2-0.4$ per 1000 children ( 1 case per 2500 - 5000 children). Then, studies carried out in the late 1990s and in the early 2000s reported annual rises in incidence of autism in pre-school children, based on age of diagnosis, and increases in the age-specific prevalence rates in children. Prevalence rates of up to 6.0 per 1000 ( 1 case per 166 children) for autism-and even more 
for the entire autistic spectrum-were reported by various state monitoring agencies. Although the general medical community accepted other reasons for these increases, including changes in diagnostic criteria, development of the concept of the wide autistic spectrum, recognition of different methods used in studies, growing awareness and knowledge among parents and professional workers and the development of specialist services, as well as the possibility of a true increase in numbers, the lay public disagreed [20].

The situation led to the development of lay advocacy groups who refused to accept other explanations for the apparent increase in the incidence of autism and sought to blame this first on Measles Mumps Rubella vaccine [21], and then on thimerosal [15] [16]. These advocacy groups were comprised primarily of parents of autistic children who appeared inclined to favor external environmental factors as a more likely cause for the increased incidence in ASD. The plaintiffs hired consultants to perform risk analysis using data provided to them by the CDC. It was later determined by the Institute of Medicine (IOM, recently renamed as the National Academy of Medicine) that these researchers had misused this data and improperly used the terms "incidence rate" and "attributable risk", in addition to coining the new term "percent association" which is not a recognized epidemiologic measure [14]. If one searches the medical literature on this topic, one would find that the incidence rates vary widely because so many factors and variables, including wide-ranging definitions of ASD and an increased awareness that lead to increased reporting of cases, have been used in these incidence calculations.

Data obtained from the CDC for autism spectrum disorders shows that the removal of thimerosal from vaccines in 2001 did not result in a decrease in the incidence of autism (see Table 1 for the prevalence of autism spectrum disorders reported by the ADDM-Autism and Developmental Disabilities Monitoring-Network for 2000-2012) [22]. Nevertheless, during 2002-2004 plaintiffs mounted a large and multifaceted effort to implicate thimerosal as the cause of the problem. Only the most important and significant research is summarized here,

Table 1. Prevalence of autism spectrum disorders ADDM (Autism and developmental disabilities monitoring) Network 2000-2012 combining data from all sites [22].

\begin{tabular}{ccccc}
\hline $\begin{array}{c}\text { Surveillance } \\
\text { year }\end{array}$ & $\begin{array}{c}\text { Birth } \\
\text { year }\end{array}$ & $\begin{array}{c}\text { Number ADDM } \\
\text { sites reporting }\end{array}$ & $\begin{array}{c}\text { Prevalence per 1000 } \\
\text { [range] }\end{array}$ & $\begin{array}{c}\text { This is about } \\
\text { 1 in \# children }\end{array}$ \\
\hline $2000^{\mathrm{a}}$ & 1992 & 6 & $6.7[4.5-9.9]$ & 1 in 150 \\
$2002^{\mathrm{b}}$ & 1994 & 14 & $6.6[3.3-10.6]$ & 1 in 150 \\
2004 & 1996 & 8 & $8.0[4.6-9.8]$ & 1 in 125 \\
2006 & 1998 & 11 & $9.0[4.2-12.1]$ & 1 in 110 \\
2008 & 2000 & 14 & $11.3[4.8-21.2]$ & 1 in 88 \\
2010 & 2002 & 11 & $14.7[5.7-21.9]$ & 1 in 68 \\
2012 & 2004 & 11 & $14.6[8.2-24.6]$ & 1 in 68 \\
\hline
\end{tabular}

${ }^{\mathrm{a} T h i m e r o s a l ~ r e m o v e d ~ f r o m ~ a l l ~ c h i l d h o o d ~ v a c c i n e s ~ e x c e p t ~ i n f l u e n z a ~ b y ~} 2001 .{ }^{\mathrm{b}}$ Thimerosal and autism litigation initiated. 
followed by the defendant's use of the literature to challenge the plaintiff's experimental findings.

As shown in Table 1, CDC's ADDM Network reported that in surveillance year 2000, the prevalence of ASD was 6.7/1000 children (1 in 150). By 2006, the prevalence of ASD increased to 9.0/1000 children (1 in 110). From 2012, with the birth year in 2004, nearly 3 years after thimerosal had been removed from vaccines, the prevalence of ASD had further increased to 14.6/1000 children (1 in 68). This means that from 2000 (the final complete year with thimerosal in vaccines) to 2006 to 2012, the estimated prevalence of ASDs increased by $34.3 \%$ and $117.9 \%$, respectively-long after thimerosal was removed from childhood vaccines. Similar epidemiological data were available in the early 2000s that showed retrospective studies conducted over a 30-year period of children who were exposed to thimerosal in vaccines had no increased incidence in autism [23]. A more recent study further showed that the prevalence of autism began to increase in the years after thimerosal was removed from vaccines [13]. There may be many reasons for this, but it seems clear that thimerosal was not the cause.

\subsection{Plaintiff Experimental Approach}

One of the first arguments made by the plaintiffs was that the well-known neurotoxic properties of methylmercury [24] [25] would be similar for ethylmercury. Accordingly, they used the guidelines for the maximum safe limit of methylmercury exposure as issued by the Environmental Protection Agency (EPA) and the FDA. The fallacy of this line of thinking is that it is generally well known that in a homologous series of alkyl congeners, the properties of the shortest alkyl group (methyl) are usually quite different from those of the longer alkyl congeners (ethyl, propyl, etc.). This is best known for the properties of methyl and ethyl alcohol. Methyl alcohol is so acutely toxic that ingestion of small quantities can lead to blindness. In contrast, ethyl alcohol, which contains only a single additional carbon atom (as a methylene moiety, $\mathrm{CH}_{2}$ ), does not cause blindness.

A literature search performed by the defendants showed that the chemical, biochemical, pharmacological and toxicological profiles of methylmercury and ethylmercury are quite different (see Table 2 for the chemical and biological properties of alkyl forms of mercury: methylmercury, ethylmercury, and propylmercury). One of the most important differences identified is marked difference in their biological half-lives (time for the plasma concentration to decrease by $50 \%$ ). The half-life for methylmercury in humans is $50-80$ days [26], whereas that for ethylmercury is $4-10$ days [27], which is another reason that the guidelines for methylmercury exposure are not applicable to ethylmercury. Another important difference that was identified is that methylmercury accumulates in the brain nearly 10 -fold more than ethylmercury, and it also has a different relative tissue distribution profile, with higher accumulation in the liver and lower accumulation in brain tissue [28] [29]. 
Table 2. Chemical and biological properties of alkyl forms of mercury ( $\mathrm{Hg})$.

\begin{tabular}{cccc}
\hline Property & Methyl-Hg & Ethyl-Hg & Propyl-Hg \\
\hline Molecular weight & 215 & 229.6 & 243 \\
$\%$ Hg content & 93.0 & 87.1 & 82.3 \\
$\begin{array}{c}\text { Half-life } \\
\text { (days, human) }\end{array}$ & $50-80[26]$ & $4-10[27]$ & - \\
$\begin{array}{c}\text { Level in brain } \\
\text { (ppm, rat) [28] }\end{array}$ & 10.4 & 1.1 & 3.0 \\
$\begin{array}{c}\text { Distribution after } \\
2 \mathrm{~d} \text { (mouse) [29] }\end{array}$ & $0.8 \%$ brain, 0.4\% spleen & $0.3 \%$ brain, 0.2\% spleen & $0.6 \%$ brain, $0.3 \%$ spleen \\
\hline
\end{tabular}

The next phase of the plaintiff's approach involved hiring expert witnesses, including chemists and pharmacologists. Each of these scientists had a clear prior opinion about mercury. One (a chemist) had devoted a significant portion of his career studying the neurotoxic effects of various forms of mercury; another was specifically hired to explore potential new biochemically toxic effects of thimerosal. Potential biases were identified by reviewing the experts' earlier publications and patents (In order to preserve their anonymity, no reference citations will be included in this section).

In the scientific phase of their strategy, the plaintiff scientists tried to find novel ways of implicating thimerosal with the neurodevelopmental aspects associated with autism. They also were able to find evidence that supported some new concepts they advanced such as their mercury retention hypothesis. They conducted their own experiments and conducted small clinical trials to show that autistic children excreted less mercury into their hair compared to non-autistic controls. No attempt was made to adjust for exposure to mercury between the two groups. Other approaches they used consisted of illogical extrapolations to neurodegenerative conditions such as Alzheimer's disease, where they claimed that these patients also had higher concentrations of mercury in certain areas of their brain.

In a video titled "How mercury causes brain degeneration", originally developed by researchers at a university, the toxicity of mercury was demonstrated by using isolated neurons obtained from snail brain tissue grown in tissue culture and then following their growth with time-exposure video photography. Under control conditions, the neurons are shown to be growing normally (sprouting new dendrites and lengthening existing ones). When a solution containing inorganic mercury ions (the specific form was not specified) was added to the tissue culture medium at $10^{-7}$ molar $(0.1 \mu$ molar, a concentration far in excess of what would normally be found in brain tissue following exposure to mercury), the neurons ceased their growth and began to retract their dendrites. The purpose of this video was to demonstrate that the direct exposure of neurons to mercury can lead to neurodegeneration, and therefore may be associated with certain neurodegenerative conditions such as Alzheimer disease. Sometime after this video was produced (2001) and after the thimerosal litigation was ongoing, a 
plaintiff law firm used this video to create a new video titled "The dangers of thimerosal". The new title could be viewed as somewhat misleading since no thimerosal was ever used in the experiment. In addition, recall that the purpose of the original video was a demonstration of mercury-induced neurodegeneration. By improperly projecting the findings with mercury to thimerosal, the effect of the remade version was to (intentionally) conflate "neurodegenerative" with "neurodevelopmental"-two very different concepts in neuropathophysiology.

Two additional questionable facets in their approach were the assumption that $100 \%$ of the thimerosal was absorbed into the circulatory system and that most, if not all, of this was able to reach the developing brain where it interfered with microtubule assembly, one of the mechanisms claimed by the plaintiffs to play a role in causing autism. One questionable assertion arose from the way they predicted brain concentrations resulting from thimerosal exposure. By assuming $100 \%$ of the thimerosal was able to reach the brain, the plaintiff scientists were essentially using a one-compartment pharmacokinetic model. Most drugs follow at the very least a two-compartment model (blood + tissue distribution), and some drugs require multiple compartment models. Mathematical equations have been developed to predict tissue concentrations for multi-compartment models, and these were not utilized by plaintiff scientists in calculations of predicted levels of mercury in the brain. Furthermore, at about the time the litigation was initiated, a paper was published showing that blood levels of mercury in infants who had received multiple vaccines containing thimerosal were not significantly elevated compared with infants vaccinated using thimerosal-free vaccines [27]. This information, although it was acknowledged by plaintiff experts, did not dissuade them from continuing with research to implicate thimerosal as the likely cause of autism.

As the litigation progressed, a cynical view is that the plaintiffs modified their hypotheses and approaches when the experimental findings failed to support the original hypothesis of mercury accumulation in the brain. Thus, they were forced to develop "the mercury retention hypothesis" when studies conducted on autistic children showed that they had little or no more mercury in their hair than did non-autistic controls (at the beginning of the litigation, they postulated that autistics should have much higher levels of mercury in their hair than normal subjects) [16]. According to the new hypothesis, the reason that little or no mercury was found in the hair of autistic children was due to the fact that they had an impaired ability to excrete the mercury and therefore more of it was retained in their body and brain tissue.

\subsection{Defendants Response to Plaintiff's Science}

Defendants thought that the plaintiff science was flawed at various levels, and thus that it would not be a difficult task to assemble medical and scientific data of a higher caliber to refute many of their claims. One important action taken by the defendants was to hire a pharmacokineticist to develop a two-compartment 
model that could be used to estimate more accurately tissue concentrations of mercury from blood samples obtained from a small sample (sample size $=7$ ) of plaintiff children. Using the model, the expert showed that predicted blood and brain concentrations of mercury were far lower than those that were proposed by the plaintiffs.

The defendants also performed literature searches and compiled a large body of data that was able to convince the courts that the plaintiff evidence was in fact weak. For example, a literature search on microtubules and autism failed to identify a single publication that investigated these two topics together. Therefore, the role of microtubules in the etiology and pathophysiology of autism had to be inferred from a general knowledge of the basic function of the microtubules and how this could possibly relate to the neuroanatomical and neurophysiological changes associated with autism. It is beyond the scope of this article to discuss the neuroanatomy and physiology associated with autism, however based on pathological findings from autistic brain tissue, autism may be defined in one way as a disorder of neuronal organization. But at the time of this litigation, there were no studies that specifically studied the role of the microtubule system in the development of autism. Additional literature evidence provided by defendants showed that numerous cellular and biochemical mechanisms protect the body against heavy metal toxicity and specifically against mercury toxicity. Although these mechanisms are insufficient to protect against an exposure to high doses or concentration of mercury, the literature clearly showed that toxic effects from small amounts of mercury exposure could be handled by these protective mechanisms [29] [30]. There were numerous additional efforts made by the plaintiff scientists, and each one was able to be refuted successfully by careful use of published studies by independent researchers who had no connection to the thimerosal litigation.

\section{Discussion}

Two cases of litigation were used here to illustrate how medical and scientific evidence, when properly used, can impact decisions rendered by juries and judges. In the diet-drug litigation, the publication in the New England Journal of Medicine [8] of a case report that consisted of 24 subjects was the initial trigger to prompt the FDA to request that the sponsor voluntarily withdraw fenfluramine from the market in September 1997. It is interesting to note that, despite sponsor's ability to generate numerous publications (in what are considered to be high-quality journals) that demonstrated that the valvular abnormalities were not as severe as originally thought, the overwhelming number of plaintiffs that came forward was sufficient to carry more weight than the clinical follow-up studies, forcing the sponsor into a class action settlement.

In contrast, in the few cases related to thimerosal that were litigated in courts, each one was dismissed and class-action status was denied after the presentation of the second Immunization Safety Review by the Institute of Medicine, issued in 2004 [14] Despite this decision, cases continued to be litigated for several 
years. In one of the final cases, tried in Circuit Court in Baltimore, Maryland in 2008, the judge ruled to prevent the plaintiffs expert witnesses from testifying that exposure to thimerosal-containing vaccines can cause autism. In his ruling, the judge asserted that "plaintiffs had failed to show that the methodologies underlying their expert witnesses' opinions are generally accepted as reliable in the scientific community." He also stated that plaintiffs expert witnesses were not qualified by "knowledge, skill, experience, training, or education... to support the causation opinions that plaintiffs wished to present to the jury" [31].

The effects of drug product-injury litigation on the financial status of a manufacturer is devastating and has a long-term effect on the business, especially when it is found guilty of marketing a defective product and must pay out large sums of money for many years. Even when the manufacturer is found innocent of the charges, it still has to incur the extra costs associated with its defense, which can easily run into the multimillion dollar range. Short- or long-term consequences are likely to result, contingent on the extent of the financial damage. Depending on one's point of view, the company may have to cut back its research and development budget, its appetite for innovative research might be diminished, the cost of drug discovery and development might rise significantly, and patients might be deprived of potentially beneficial medications. On the other side, drug-product litigation-whether won or lost-drives the system toward safer drugs.

\section{Conclusion}

The fallout from drug product-injury litigation can have a significant financial impact on the manufacturing company, and may disincentivize innovation and possibly discovery of more effective medications. On the other hand, because of the potential for devastating financial damage, large pharmaceutical manufacturers now routinely develop clinical risk management plans as part of the drug development process. This new aspect of drug development, when combined with the ongoing post-marketing surveillance of newly approved drugs as well as those previously approved for marketing, should decrease the risks associated with long-term use of a drug, help in the early identification of adverse events not previously identified in clinical trials, and ideally decrease the extent of drug-product liability litigation. It is recommended that the decision of individual cases will rely on the appropriate use of the medical literature, clinical trial data, and experimental research (as well as additional factors). The significance is that in the long run, this should provide an impetus for-and marketing of-the safest drugs possible.

\section{Disclosures}

J.K. is a former employee of Wyeth Pharmaceuticals (Pfizer, Inc) and was actively involved in various cases of drug product-injury litigation from 1997-2005. He has no financial interest associated with any of the information presented in 
this manuscript. J.P. has acted as a consultant, researcher, and/or speaker for Inspirion, Mallinckrodt, DSI, Grünenthal, BDSI, Depomed, Adapt Pharma and Salix. He is also and partner in CaRafe and cofounder of Neumentum. R.T. has nothing to declare. R.R. was a previous employee of Johnson \& Johnson and has received research support and honoraria from several other pharmaceutical companies involved in analgesics research and development-but he receives no remuneration based on sales of any product. He is a cofounder of CaRafe Drug Innovation (involved in the discovery of non-opioid analgesics) and advisor/investor with Neumentum (non-opioid analgesics). The authors have no other relevant affiliations or financial involvement with any organization or entity with a financial interest in or financial conflict with the subject matter or materials discussed in the manuscript apart from those disclosed.

\section{References}

[1] Lamb, T. (2018) Drug Injury Watch. http://www.drug-injury.com/

[2] FDA (2018) Reports Received and Reports Entered into FAERS by Year. https://www.fda.gov/drugs/guidancecomplianceregulatoryinformation/surveillance/ adversedrugeffects/ucm070434.htm

[3] Daubert v. Merrell Dow Pharmaceuticals, Inc. (1993) U.S. Supreme Court, 509 U.S. 579, No. 92-102.

[4] Kumho Tire Company, Ltd. v. Carmichael. (1999) U.S. Supreme Court, 131 f.3d 1433, No. 97-1709.

[5] Reference for Business (2018) Product Liability. http://www.referenceforbusiness.com/small/Op-Qu/Product-Liability.html

[6] James, P., Oparil, S., Carter, BL., et al. (2014) Evidence-Based Guideline for the Management of High Blood Pressure in Adults: Report from the Panel Members Appointed to the Eighth Joint National Committee (JNC 8). Journal of the American Medical Association, 311, 507-520. https://doi.org/10.1001/jama.2013.284427

[7] Ascione, F.J. (2001) Principles of Scientific Literature Evaluation: Critiquing Clinical Trials. American Pharmaceutical Association, Washington DC.

[8] Connolly, H.M., Crary, J.L., McGoon, M.D., et al. (1997) Valvular Heart Disease Associated with Fenfluramine-Phentermine. The New England Journal of Medicine, 337, 581-588.

[9] Gardin, J.M., Weissman, N.J., Leung, C., et al. (2001) Clinical and Echocardiographic Follow-Up of Patients Previously Treated with Dexfenfluramine or Phentermine/Fenfluramine. Journal of the American Medical Association, 286, 2011-2014.

[10] Steffee, C.H., Singh, H.K. and Chitwood, W.R. (1999) Histologic Changes in Three Explanted Native Cardiac Valves Following Use of Fenfluramines. Cardiovascular Pathology, 8, 245-253. https://doi.org/10.1016/S1054-8807(99)00019-8

[11] Rothman, R.B., Baumann, M.H., Savage, J.E., et al. (2000) Evidence for Possible Involvement of $5-\mathrm{HT}_{2 \mathrm{~B}}$ Receptors in the Cardiac Valvulopathy Associated with Fenfluramine and Other Serotonergic Medications. Circulation, 102, 2836-2841. https://doi.org/10.1161/01.CIR.102.23.2836

[12] Sackett, D.L., Straus, S.E., Richardson, W.S., Rosenberg, W. and Haynes, R.B. (2000) 
Evidence-Based Medicine: How to Practice and Teach EBM. 2nd Edition, Churchill Livingstone, Edinburgh.

[13] Schechter, R. and Grether, J.K. (2008) Continuing Increases in Autism Reported to California's Developmental Services System. Archives of General Psychiatry, 65, 19-24.

[14] Institute of Medicine (2004) Immunization Safety Review: Vaccines and Autism. National Academies Press, Washington DC.

[15] Bernard, S., Enayati, A., Redwood, L., Roger, H. and Binstock, T. (2001) Autism: A Novel Form of Mercury Poisoning. Medical Hypotheses, 56, 462-471.

[16] Bernard, S., Enayati, A., Roger, H., Binstock, T. and Redwood, L. (2002) The Role of Mercury in the Pathogenesis of Autism. Molecular Psychiatry, 7, S42-S43. https://doi.org/10.1038/sj.mp.4001177

[17] Suzuki, T., Miyama, T. and Katsunuma, H. (1963) Comparative Study of Bodily Distribution of Mercury in Mice after Subcutaneous Administration of Methyl, Ethyl and N-Propyl Mercury Acetates. Japanese Journal of Experimental Medicine, 33, 277-282.

[18] Centers for Disease Control and Prevention (1999) Thimerosal in Vaccines: A Joint Statement of the American Academy of Pediatrics and the Public Health Service. MMWR. Morbidity and Mortality Weekly Report, 48, 563-565. https://www.cdc.gov/mmwr/preview/mmwrhtml/mm4826a3.htm

[19] Kanner, L. (1943) Autistic Disturbances of Affective Contact. Nervous Child, 2, 217-250.

[20] Wing, L. and Potter, D. (2002) The Epidemiology of Autistic Spectrum Disorders: Is the Prevalence Rising? Mental Retardation and Developmental Disabilities Research Reviews, 8, 151-161.

[21] Wakefield, A.J., Murch, S.H., Linnell, A.A.J., et al. (1998) Ileal-Lymphoid-Nodular Hyperplasia, Non-Specific Colitis and Pervasive Developmental Disorder in Children. The Lancet, 351, 637-641. https://doi.org/10.1016/S0140-6736(97)11096-0

[22] CDC (2018) Data and Statistics. https://www.cdc.gov/ncbddd/autism/data.html

[23] Madsen, K.M., Lauritsen, M.B., Pedersen, C.B., et al. Thimerosal and the Occurrence of Autism: Negative Ecological Evidence from Danish Population-Based Data. Pediatrics, 112, 604-606. https://doi.org/10.1542/peds.112.3.604

[24] Bakir, F., Damluji, S.F., Amin-Zaki, L., et al. (1973) Methylmercury Poisoning in Iraq. Science, 181, 230-241. https://doi.org/10.1126/science.181.4096.230

[25] Kurland, L.Y., Faro, S.N. and Siedler, H. (1960) Minamata Disease: The Outbreak of a Neurologic Disorder in Minamata, Japan, and Its Relationship to the Ingestion of Seafood Contaminated by Mercurial Compounds. World Neurology, 1, 370-375.

[26] Institute of Medicine (2001) Immunization Safety Review: Thimerosal-Containing Vaccines and Neurodevelopmental Disorders. National Academy Press, Washington DC.

[27] Pichichero, M.E., Cernichiari, E., Lopreiato, J. and Treanor, J. (2002) Mercury Concentrations and Metabolism in Infants Receiving Vaccines Containing Thiomersal: A Descriptive Study. The Lancet, 360, 1737-1741. https://doi.org/10.1016/S0140-6736(02)11682-5

[28] Nose, K. (1969) Studies on the Toxicity of Low Alkyl Mercury Compounds. Japanese Journal of Hygiene, 24, 359-367. https://doi.org/10.1265/jjh.24.359

[29] Suzuki, K., Nakajima, K., Otaki, N. and Kimura, M. (1994) Metallothionein in De- 
veloping Human Brain. Neurosignals, 3, 188-192.

https://doi.org/10.1159/000109544

[30] Monks, T.J., Ghersi-Egea, J.F., Philbert, M., Cooper, A.J. and Lock, E.A. (1999) Symposium Overview: The Role of Glutathione in Neuroprotection and Neurotoxicity. Toxicological Sciences, 51, 161-177. https://doi.org/10.1093/toxsci/51.2.161

[31] Blackwell et al. v. Sigma Aldrich, Inc. (2008) Thimerosal-Autism Link Rejected by Maryland Court. Wyeth Press Release 14 January. 